ñTriplex formation using oligonucleotide clamps carrying 8-aminopurinesò Aviñó, A., Grimau, M.G., Alvira, M., Eritja, R., Gargallo, R., Orozco, M., González, C. Nucleosides, Nucleotides \& Nucleic Acids, 26(8-9), 979-983 (2007).

doi: 10.1080/15257770701508398

\title{
Triplex formation using oligonucleotide clamps carrying 8-aminopurines
}

Anna Aviñó ${ }^{1,2}$, Marta G. Grimau ${ }^{1,2}$, Margarita Alvira ${ }^{1,2}$, Ramon Eritja ${ }^{1,2}$, Raimundo Gargallo $^{3}$, Modesto Orozco ${ }^{2,3}$, Carlos González ${ }^{4}$

${ }^{1}$ Instituto de Biologia Molecular de Barcelona. C.S.I.C., Jordi Girona 18-26, 08034 Barcelona, Spain.

${ }^{2}$ Institute for Research in Biomedicine (IRB), Barcelona. Parc Científic de Barcelona, Josep Samitier 1-5, 08028 Barcelona, Spain.

${ }^{3}$ Facultat de Química. Universitat de Barcelona. Martí i Franqués 1-11, E-08028 Barcelona, Spain.

${ }^{4}$ Instituto de Química Física Rocasolano. C.S.I.C. Serrano 116. E-28006 Madrid. Spain

\section{Running Title: oligonucleotide clamps carrying 8-aminopurines}

\begin{abstract}
The synthesis and properties of triplex-forming DNA clamps carrying 8aminopurines are described. The stability of triple helices is enhanced by replacing purine bases with 8-aminopurine residues. These enhanced binding properties are used for the specific capture of polypyrimidine RNA/ DNA sequences of interest.
\end{abstract}

Introduction. A triple helix is a structure that appears when a DNA duplex containing a polypurine track interacts with a third strand by means of specific $\mathrm{H}$-bonds in the major 
groove of the duplex. Several biomedical (antigene strategy) and biotechnological applications based on triplex formation have been described (1).

Depending on the orientation of the third strand with respect to the central polypurine Watson-Crick (WC) strand, triplexes are classified by two main categories i) parallel or pyrimidine triplex motif and ii) antiparallel or purine triplex motif (1). Most structural studies on DNA triplexes have focused on parallel triplexes, which under normal laboratory conditions are more stable than the corresponding antiparallel triple structures. In order to enhance triple helix binding stability we have focused in preparing oligonucleotides containing 8-aminopurines. The introduction of an amino group at position 8 of the adenine and guanine increases stability due to the combined effect of the gain of one Hoogsteen purine-pyrimidine H-bond and the propensity of the amino group to be integrated into the ñspine of hydratationò located in the minor groove of the triplex structure $(2,3)$.

An alternative approach to the generation of oligonucleotide-derived DNA-, or RNAbinding molecules is based on triplex formation via the linkage of one Watson-Crick strand with the third strand or triplex forming oligonucleotide (TFO). Such DNA clamps bind single-stranded nucleic acid targets by triplex formation (4, scheme 1). This strategy has been further developed to bind double-stranded DNA by strand displacement using PNA derivatives. In this case, the driving force is the high stability of PNA-PNA-DNA triplexes (5).

In this communication we describe the synthesis and triplex-forming properties of DNA clamps carrying 8-aminopurines. We show that the stability of triple helices is enhanced by replacing purine bases with 8 -aminopurine residues. These enhanced binding properties are used for the specific capture of polypyrimidine RNA/ DNA sequences of interest. 


\section{Results and Discussion}

Parallel Clamps. Sequence-specific triple-helix structures can be formed by DNA clamps. Parallel-stranded DNA clamps (6) consist of purine residues linked to a homopyrimidine chain of inverted polarity by 3ô3ô or 5ô5ôinternucleotide junctions (scheme 1), which interact with single-stranded homopyrimidine nucleic acid targets (7). In this type of triplex, the homopurine strand binds the homopyrimidine target through Watson-Crick bonds; and the clamp homopyrimidine strand, which binds via Hoogsteen bonding, is stabilized under acidic conditions. The parallel-stranded oligomers were prepared following previously described protocols (6-8). For example, the preparation of 3ô3ôhairpins was performed in three parts: First, the purine part, using $\mathrm{G}$ and $\mathrm{A}$ phosphoramidites and 8-aminopurine phosphoramidites $(2,3)$ was prepared. After the assembly of the purine part, an hexaethyleneglycol linker or a short oligonucleotide sequence was added to form a loop. And, finally, the pyrimidine part was assembled using reversed $\mathrm{C}$ and $\mathrm{T}$ phosphoramidites (6-8). The relative stability of triple helices formed by oligonucleotide clamps and the polypyrimidine target sequence were measured spectrophotometrically at different $\mathrm{pHs}(\mathrm{pH}$ 5.5-7.0). The target sequence was a polypyrimidine sequence of 11 bases $(2,3)$. In all cases one single transition was observed with a hyperchromicity around $25 \%$ at acidic $\mathrm{pH}$ and $20 \%$ at neutral $\mathrm{pH}$. The melting curve was assigned to the transition from triple helix to random coil. Replacement of $\mathrm{A}$ and $\mathrm{G}$ by 8 -aminoadenine and 8 -aminoguanine in the triple helix, results in a high stabilization $\left(2-10^{\circ} \mathrm{C}\right.$ per substitution in the range from $\mathrm{pH} 5.5$ to $\mathrm{pH} 7.0$, scheme 2) (8). The strongest stabilizing effect was found on 8-aminoguanine and at neutral pH. Furthermore, 8-aminoguanine and 8-aminoadenine are also stabilizing Hoogsteen parallel-stranded duplex structures (9). 


\section{Antiparallel clamps.}

This same strategy has been proven to generate stable antiparallel triplexes using purine-rich clamps as templates (i.e. antiparallel-clamps). Antiparallel clamps formed by a G,A- or G,T-Hoogsteen sequence linked to a polypurine sequence carrying 8aminopurines have also been prepared (scheme 1) (10) and shown to form more stable triplexes if 8-aminoguanine is present in the purine Watson-Crick position (scheme 3). The presence of 8-aminoadenine stabilizes antiparallel clamps carrying G,T-Hoogsteen strand (scheme 3) (10).

\section{Applications based on triplex formation}

The increased binding properties of clamps carrying 8-aminopurines may be of special interest for the development of applications based on triple-helix formations. One of the first applications involved capture of the cauliflower mosaic virus $35 \mathrm{~S}$ promoter sequence by 8-aminopurine oligonucleotide clamps carrying biotin (11). The presence of this sequence serves as a marker for genetically modified organisms (GMO) in food. The cauliflower mosaic virus $35 \mathrm{~S}$ promoter sequence features a 12-base polypyrimidine target. Binding of oligonucleotide clamps was prevented by the targetô secondary structure. Moreover we have demonstrated that adding a tail sequence to the WatsonCrick strand in such modified clamps (tail-clamps, scheme 1) overcomes structural interferences, while simultaneously increasing the stability of triplex formation to a high degree.

A similar result was found during the development of capture probes for the detection of bacteria on food. We synthesized parallel tail-clamps (scheme 1) designed to bind with Listeria innocua iap mRNA sequences containing a polypyrimidine track (12). Our 
aim was to obtain optimum conditions for the triplex affinity capture of Listeria innocua iap mRNA sequences in order to develop new detection methods for pathogens based on the specific identification of their nucleic acids. In our study, we explored the effects of $\mathrm{pH}$ on the interaction of parallel tail-clamps with their target by UV thermal melting analysis. Optimal results were obtained with tail-clamps carrying 8-aminoadenine moieties under neutral $\mathrm{pH}$ conditions: $45 \%$ of the iap mRNA molecules from a total RNA solution were captured (12).

Project financed by E.E.C.C. STRP 014006 Nano3D, by Fundació La Caixa BM04-520 and by Spanish Ministry of Education BFU2005-23719-E, NAN2004-09415-C05-03 and BFU2004-02048.

\section{References}

1. Thuong, T., and Hélène, C., 1993. Angew. Chem. Int. Ed. Engl., 32, 666-690.

2. Güimil-García, R., Ferrer. E., Macías, M.J., Eritja, R., and Orozco, M. 1999. Nucleic Acids Res. 27, 1991-1998.

3. Soliva, R., Güimil García, R., Blas, J.R., Eritja, R., Asensio, J.L., González, C., Luque, F.J., and Orozco, M. 2000 Nucleic Acids Res. 28, 4531-4539

4. Prakash, G., and Kool, E.T., 1991. J. Chem. Soc. Chem. Commun., 646, 1161-1162.

5. Nielsen, P.E., Egholm, M., Berg, R., and Buchardt, O., 1991. Science, 254, 14971500.

6. Van de Sande, J.H., Ramsing, N.B., Germann, M.W., Elhorst, W., Kalisch, B.W., Kitzing, E.V., Pon, R.T., Clegg, R.C., and Jovin, T.M. 1988. Science, 241, 551-557.

7. Kandimalla, E.R., and Agrawal, S. 1996. Biochemistry, 35, 15332-15339. 
8. Aviñó, A., Frieden, M., Morales, J.C., de la Torre, B.G., Güimil-García, R., Azorín, F., Gelpí, J.L., Orozco, M., González, C., and Eritja, R. 2002. Nucleic Acids Res., 30, 2609-2619.

9. Cubero, E., Aviñó, A., de la Torre, B.G., Frieden, M., Eritja, R., Luque, F.J., González, C., and Orozco, M. 2002. J. Am. Chem. Soc., 124, 3133-3142.

10. Aviñó, A., Cubero, E., González, C., Eritja, R., and Orozco, M. 2003. J. Am. Chem. Soc., 125, 16127-16138.

11. Nadal, A., Eritja, R., Esteve, T., and Plà, M. 2005. ChemBioChem, 6, 1034-1042.

12. Nadal, A., Coll, A., Aviñó, A. Esteve, T., Eritja, R., and Plà, M. 2006. ChemBioChem, 7, 1039-1047. 
FIGURE LEGENDS

Scheme 1. Schematic representation of triplexes formed by triplex forming oligonucleotides as well as by parallel and antiparallel clamps and tail-clamps.

Scheme 2. Schematic representation of parallel triplex triads involving a) 8aminoadenine and b) 8-aminoguanine. Increased on melting temperatures $(\Delta \mathrm{Tm})$ observed by the presence of 8 -aminopurines in the corresponding parallel triplex.

Scheme 3. Schematic representation of antiparallel triplex triads involving a) 8aminoguanine and b) 8-aminoadenine. Increased on melting temperatures $(\Delta \mathrm{Tm})$ observed by the presence of 8-aminopurines in the corresponding antiparallel triplex 
Scheme 1

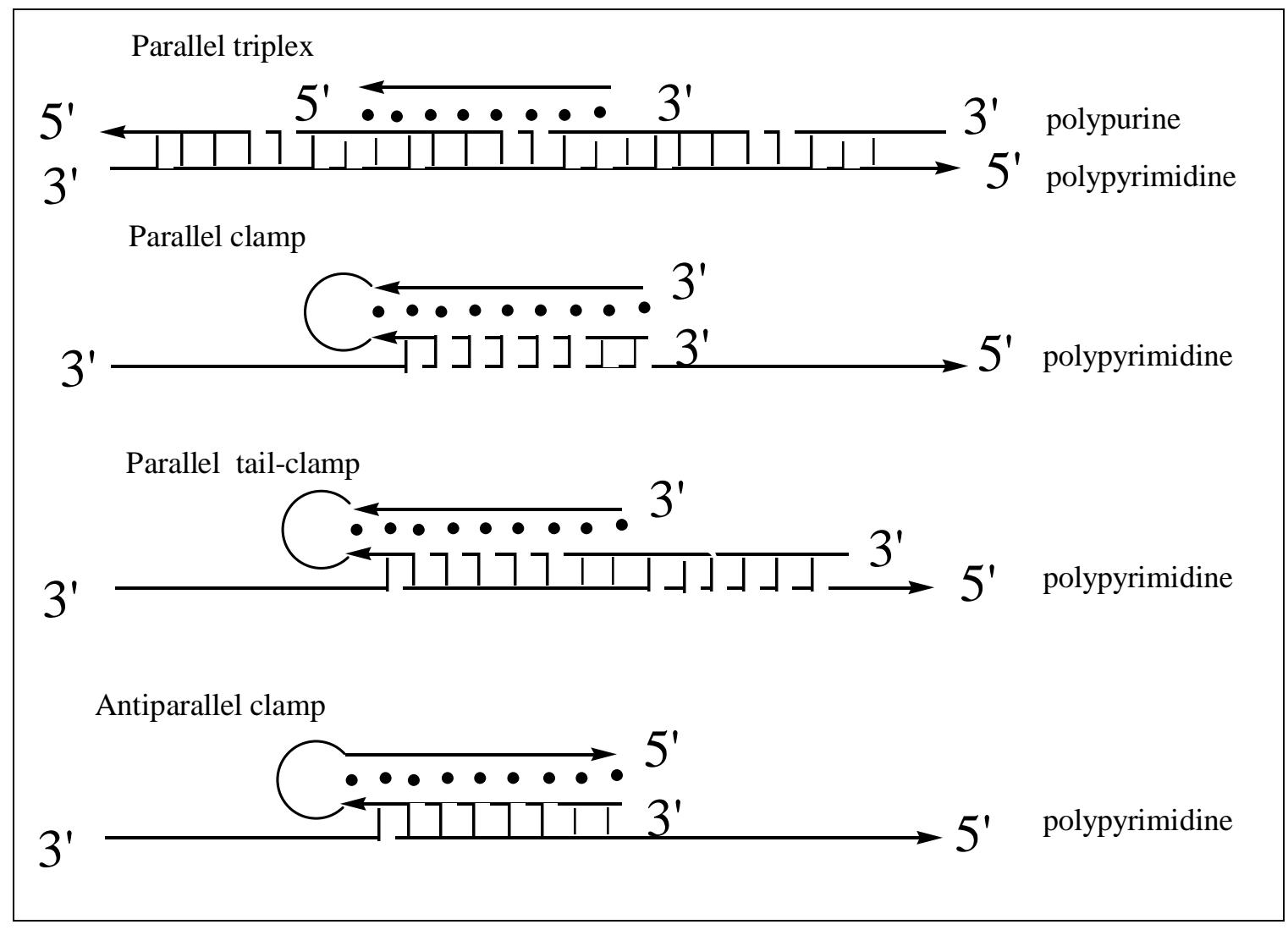


Scheme 2


$\Delta \mathrm{Tm}=$ from $+2(\mathrm{pH} \mathrm{5.5})$ to $+7^{\circ} \mathrm{C}(\mathrm{pH} 7.0)$ per substitution

$\Delta \mathrm{Tm}=$ from $+7(\mathrm{pH} \mathrm{5.5})$ to $+10^{\circ} \mathrm{C}(\mathrm{pH} 7.0)$ per substitution 
Scheme 3

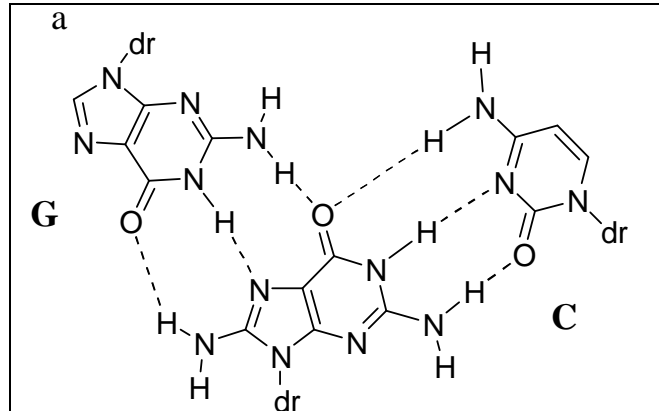

8-amino-G

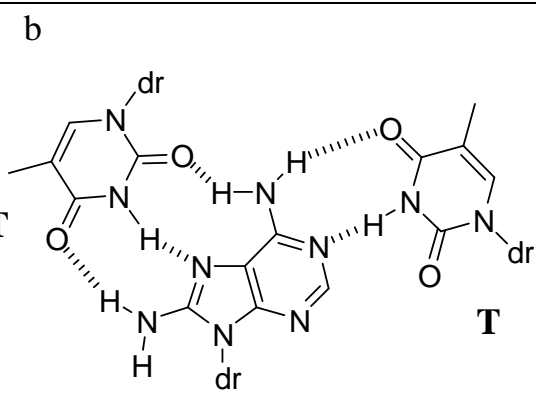

8-amino-A

$\Delta \mathrm{Tm}=+3^{\circ} \mathrm{C}$ per substitution 